\title{
Correction to: FeaturEyeTrack: automatic matching of eye tracking data with map features on interactive maps
}

\author{
Fabian Göbel $^{1} \cdot$ Peter Kiefer $^{1} \cdot$ Martin Raubal $^{1}$
}

Published online: 2 May 2019

(C) Springer Science+Business Media, LLC, part of Springer Nature 2019

\section{Correction to: Geoinformatica \\ https://doi.org/10.1007/s10707-019-00344-3}

The original version of this article unfortunately contained a mistake. Figure 10a and b were interchanged during the publishing process. The correct version of Fig. 10a, b is given below.

The original article has been corrected.

The online version of the original article can be found at https://doi.org/10.1007/s10707-019-00344-3

Fabian Göbel

goebelf@ethz.ch

Peter Kiefer

pekiefer@ethz.ch

Martin Raubal

mraubal@ethz.ch

1 ETH Zurich, Institute of Cartography and Geoinformation, CH-8093 Zurich, Switzerland 


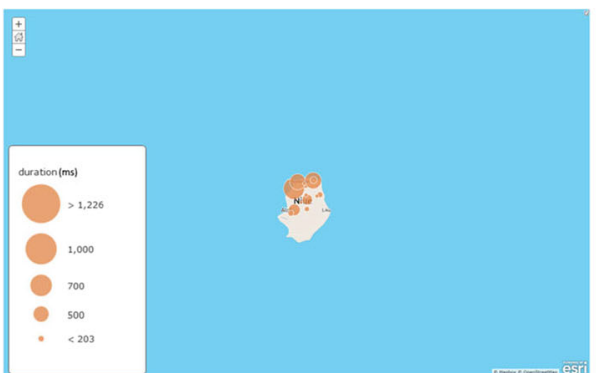

(a)

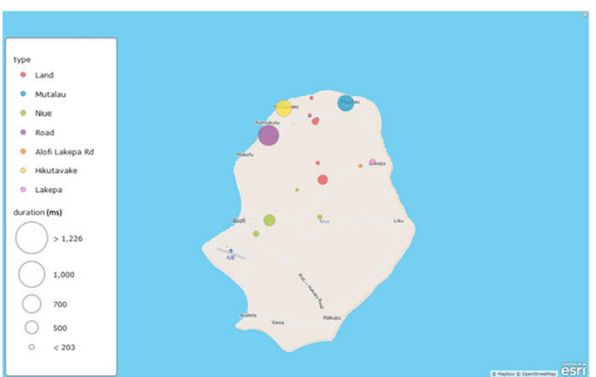

(b)

Fig. 10 A representation of the participant's fixations while performing Task 3 on an interactive map. The size of the circle represents the duration of a fixation. Visualization is produced from FeaturEyeTrack's fixation log utilizing ArcGIS Online. The same fixations are in $\mathbf{b}$ however zoomed in and enriched with information on the feature type gathered through FeaturEyeTrack

Publisher's note Springer Nature remains neutral with regard to jurisdictional claims in published maps and institutional affiliations. 